\title{
Situações de conflito e violência em escolas públicas: Aproximações entre Brasil e Portugal
}

Situations of Conflict and Violence in Public Schools: Approximations Between Brazil and Portugal

\author{
Angela Maria Martins e Mariana Gaio Alves'
}

\section{Resumo}

Este artigo analisa estratégias que escolas públicas utilizam em situações de conflito e violência e como professores, direção e alunos se organizam para enfrentá-las. Em São Paulo/Brasil, a pesquisa foi realizada em escolas públicas da rede estadual paulista que aderiram ao Programa Sistema de Proteção Escolar (SPE); em Lisboa/Portugal, foram priorizadas escolas localizadas em Territórios Educativos de Intervenção Prioritária (TEIP). Trata-se de estudo qualitativo, com base em informações de documentos oficiais e de legislação no Brasil e em Portugal, além da realização de entrevistas com equipes de gestão e professores. Considerando-se que são dois programas de governo em processo de implementação, aponta-se a relevância de auscultar os atores educacionais envolvidos nos referidos programas. Após a sistematização dos dados foram estruturadas as seguintes dimensões de análise: a) programas de governo em ação: diretrizes e normativas; b) a escola face às particularidades das comunidades em que estão localizadas: os casos estudados.

\section{Palavras chave}

Políticas públicas de educação, programas de governo, indisciplina, conflito e violência em escolas públicas.

\section{Abstract}

This article analyzes strategies that public schools use in situations of conflict and violence and how teachers, management and students organize to confront them. In São Paulo/Brazil, the research was carried out in public schools of the State of São Paulo that joined the Program for School Protection System (SPE); in Lisbon/Portugal, priority was given to schools located in Educational Territories of Priority Intervention (TEIP). This is a qualitative study, based on information from official documents and legislation in Brazil and Portugal, as well as interviews with management teams and teachers. Considering that there are two government programs in the process of implementation, it is pointed out the importance of listening to the educational actors involved in these programs.After the data were systematized the following dimensions of analysis were structured: a) government programs in action: guidelines and regulations; b) the school in view of the particularities of the communities in which they are located: the cases studied.

Key words

Public education policies, government programs, indiscipline, conflict, and violence in public schools.

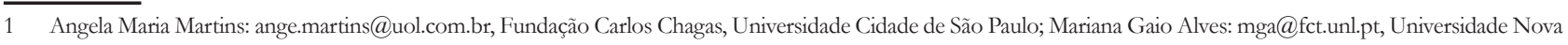
de Lisboa 


\section{Introdução}

Este artigo examina elementos que se aproximam (e/ou que se distanciam) no processo de constituição de sentidos atribuídos por profissionais de escolas públicas no Brasil e em Portugal às situações de conflito e violência. No caso brasileiro, as escolas focalizadas compõem um programa de governo intitulado Sistema de Proteção Escolar (SPE), implantado por meio da Resolução SE 19, de 12/02/2010, cujo objetivo central é instaurar na rede pública de escolas estaduais paulistas, ações para prevenir, mediar e resolver conflitos em unidades localizadas em regiões vulneráveis, do ponto de vista econômico e social. Em Portugal, as escolas selecionadas integram o programa TEIP (Territórios de Intervenção Prioritária), desde 1996, cujo objetivo central se assemelha ao SPE. Propõe-se o seguinte questionamento central: quais são as estratégias que escolas públicas -localizadas em regiões consideradas vulneráveis de acordo com as diretrizes dos programas em pauta- utilizam em situações de conflito como se organizam nas relações cotidianas entre professores, direção e alunos para enfrentá-las?

Analisar a violência na escola remete para concepções sociais contemporâneas sobre a escola, a infância e a juventude na modernidade avançada. Neste âmbito, vale destacar que a violência na escola é frequentemente retratada como um fenómeno que surge associado a certa degradação civilizacional e à massificação escolar (em especial tendo em conta o alargamento da escolaridade obrigatória), bem como a noções que veem as escolas como locais que protegem de possíveis riscos a infância e a juventude-segmentos que merecem atenção especial de proteção (Sebastião, 2013).

Sebastião, Alves, \& Campos (2003; 2010) afirmam que, no caso específico de Portugal, ocorrem insistentes debates sobre as questões que afetam o sistema de educação nacional, imensamente ampliados pela midia, sobretudo no que se refere ao termo bullying. Os autores identificam que o referido termo pode descrever qualquer tipo de situação de violência ou mesmo de indisciplina, alterando, inclusive, o significado que o qualifica como um fenômeno que envolve agressões feitas de forma sistemática e intencional. Sublinham também que as escolas, para solicitar apoio na resolução das situações de indisciplina, conflito e violência, podem solicitar sua inclusão em programas específicos, tal como o das Escolas TEIP (Territórios Educativos de Intervenção Prioritária) em processo semelhante ao que ocorre no Programa Sistema de Proteção Escolar, implementado pela Secretaria de Estado da Educação de São Paulo.

Todavia, diversos autores em vários países têm vindo a argumentar que a violência é um elemento integrante da vida nas escolas em todas as regiões e tempos históricos e nos seus vários espaços físicos (Blaya, 2008; Woods, 2001), sendo que na contemporaneidade é também relevante considerar que as tecnologias, designadamente telemóveis e internet, permitem a manifestação e ampliação de situações de conflito -cyberbullying (Slonje, Smith, 2008) - que podem prolongar-se na interação face-a-face.

Deste modo, partimos nesta pesquisa do pressuposto de que as situações de conflito são um elemento integrante da vida de qualquer escola, importando compreender como é que unidades localizadas em regiões vulneráveis se organizam por forma a prevenir e regular essas ocorrências. Assim sendo, privilegiou-se a auscultação dos professores e outros profissionais das escolas sobre as questões da indisciplina e violência, explorando as respectivas perspectivas e lógicas de ação e, adicionalmente, contribuindo para esclarecer os sentidos da sua atuação profissional nas escolas na contemporaneidade. Aliás, numa meta-análise de pesquisas doutorais realizadas em Portugal reúnem-se indícios de que a investigação sobre conflitos e convivência na escola tem privilegiado a auscultação dos alunos, sugerindo-se que deverá ser benéfico o desenvolvimento de pesquisas que auscultem os professores e outros atores escolares (Alves, 2016). 
A relevância desta abordagem de pesquisa é particularmente evidente quando entendemos a violência na escola como um «arranjo relacional» (Sebastião, 2013), ou seja, como um fenómeno multidimensional nas suas causas e consequências, o qual decorre da interação entre os diversos atores escolares em contextos escolares específicos. Nestas circunstâncias, não é de estranhar que as situações de conflito não se distribuam uniformemente por todas as escolas dentro de um determinado sistema educativo, pois os modos de organização interna das escolas têm influência nas relações de convivência entre professores, direção e alunos, bem como na ocorrência de situações de conflito.

De facto, diferentes processos de tomada de decisão no interior da escola estão associados a diferentes estratégias de prevenção e regulação da violência, constatando-se que os processos de decisão mais centralizados tendem a associar-se a estratégias mais repressivas, enquanto os menos centralizados coexistem com estratégias menos repressivas (Sebastião, 2013). Assim sendo, importa considerar a intervenção das instituições formais (caracterizando os sistemas de regras e de regulação da violência) e a importância das práticas e culturas de socialização nessas instituições. Trata-se, afinal, de rejeitar tanto as abordagens em que a violência é entendida como o resultado mecânico de processos de socialização com determinadas características, como as abordagens em que a mesma é entendida como expressão de uma patologia. Noutros termos, pretende-se com este artigo contribuir para a análise de processos de interação nas escolas explorando possíveis aproximações entre unidades situadas em regiões vulneráveis em São Paulo/ Brasil e em Lisboa/Portugal, considerando aspectos formais relacionados com enquadramentos normativos e aspectos informais ligados às culturas escolares.

A centralidade atribuída aos modos de organização e funcionamento das escolas na abordagem delineada reforça a importância de refletir sobre o papel dos professores nessas organizações, nomeadamente enquanto atores que previnem e regulam a violência na escola. Essa reflexão é particularmente pertinente na contemporaneidade, pois um certo entendimento tradicional da figura de professor enquanto autoridade e transmissor de conhecimento parece ter vindo a ser objeto de alguma erosão (Biesta, 2012). Não obstante, enquanto algumas perspectivas conservadoras argumentam que estamos perante uma alegada perda de autoridade dos professores na sociedade contemporânea, outras visões defendem que a autoridade do professor, mais do que como exercício de controlo e imposição sobre os outros, deve ser entendida como uma dinâmica relacional na qual a necessidade de articular conteúdos, relações e finalidades na ação do professor, ou noutros termos a articulação entre meios e fins da educação, é fulcral para estabelecer o que é «educacionalmente desejável» (Biesta, 2012).

Importa sublinhar que estas tensões entre visões contrastantes sobre o papel do professor na escola contemporânea coexistem com tendências transnacionais, observáveis nos últimos anos, no sentido do aumento da precariedade do trabalho e da insatisfação profissional dos professores. Com efeito, alguns estudos concluem que a precarização crescente do emprego é um dos elementos que explica o fato de os professores em geral não terem a intenção de permanecer toda a vida no ensino (Akkari,Tardif, 2011), assim como a baixa remuneração (que se tem vindo a agravar nos anos mais recentes no Brasil e em Portugal) é apontada como uma das fontes de insatisfação dos professores em diferentes contextos (Perkins, 1991; Clarke, Keating, 1995). Aliás, um estudo sobre os diplomados de ensino superior pelas duas maiores universidades de Lisboa permitiu concluir que, entre os que terminaram cursos que habilitam para a profissão de professor de ensino básico e secundário, os níveis salariais médios são menos elevados e é mais evidente a tendência de precarização dos vínculos contratuais, ainda que estes docentes se manifestem ligeiramente mais satisfeitos com a profissão do que os diplomados de outros cursos (Alves, Azevedo, 
Gonçalves, 2014). De facto, existem indícios de que as oportunidades de criatividade, de trabalhar com os mais jovens e de desempenhar uma profissão socialmente útil, assim como o facto de que ensinar envolve um contributo para a aprendizagem e desenvolvimento de outros indivíduos, parecem constituir fontes de motivação significativas para os professores revelando configurações específicas desta profissão.

\section{Metodologia}

Realizar estudos comparados no cenário contemporâneo configura-se como perspectiva relevante, ainda que afastar-se de seu próprio ponto de observação e de sua sociedade em particular não seja tarefa fácil. Contudo, no campo das ciências humanas e sociais não podemos generalizar a partir de um único fato ou processo histórico e este movimento já implica em comparação, possibilitando a passagem da explicação para a compreensão histórica e sociológica. Nessa direção, é possível traçar caminhos que possibilitem lançar mão de elementos comparativos, considerando semelhanças e diferenças entre os elementos comparados, assim como das nuances entre um polo e outro. Em estudos de caso, elementos comparativos possibilitam ainda o adensamento da reflexão sobre as singularidades e peculiaridades da sociedade/ fenômeno analisado na medida em que permite discernir traços comuns (semelhantes) e diferentes dos outros casos observados, daquilo que é meramente incidental (Cardoso, Brignoli, 1979)

No cenário contemporâneo, os estudos comparados podem ter sua viabilidade facilitada, pois, as diretrizes que fundamentam programas e projetos de governo em diferentes países e continentes, assim como as propostas de organismos internacionais, têm ampla divulgação por meio das tecnologias de informação e comunicação. Em outros termos, a análise de políticas educacionais e a realização de estudos comparados ganha outro aspecto tendo em vista a facilidade de acesso a documentos oficiais, ao escopo legal, aos dados de desempenho de alunos e de fluxo nos sistemas de ensino, disponibilizados em sites de agências financiadoras e Ministérios de Educação.

No campo das políticas educacionais, ressalte-se a relevância de ouvir o que pensam os profissionais da área sobre os programas, projetos e diretrizes de governo, pois estes podem aceitar e/ou reinterpretar esses processos de acordo com grupos de interesses.

A investigação original -da qual este artigo é um desdobramento ${ }^{2}$ - configura-se como um estudo qualitativo, lançando mão da triangulação, conforme discutido por Stake, (2011): análise de diretrizes dos documentos oficiais e da legislação no Brasil e em Portugal, tendo em vista que a recolha de dados teve lugar em escolas abrangidas por dois programas de governo em processo de implementação; identificação de resultados de estudos que focalizaram o tema; entrevistas realizadas no Brasil e em Portugal.

No Brasil, a pesquisa de campo cumpriu os seguintes procedimentos: aplicação de instrumento semiestruturado para 80 diretores; 103 professores mediadores comunitários escolares (PMECs); 103 alunos de escolas públicas inscritas no Sistema de Proteção Escolar (SPE) no estado de São Paulo/Brasil. Também se procedeu à realização de dinâmicas de grupo com diretores e professores mediadores comunitários. Neste artigo serão analisados apenas os dados relativos aos diretores.

Em Portugal, foram entrevistados dez profissionais que integram equipes de gestão de três agrupamentos de escolas localizadas na área de Lisboa, por meio de roteiro semi-estruturado: num agrupamento

2 A investigação maior na qual este trabalho se insere intitula-se «Conflitos no espaço escolar: a gestão de escolas públicas em contextos vulneráveis», financiada pelo Conselho Nacional de Desenvolvimento Científico e Tecnológico (CNPq), agência do Ministério da Ciência, Tecnologia, Inovações e Comunicações (MCTIC) do Brasil. 
da zona norte de Lisboa foram entrevistadas duas adjuntas do diretor, bem como uma coordenadora do plano TEIP e uma coordenadora de diretores de turma; num agrupamento situado na zona sul de Lisboa foi entrevistada a diretora e duas técnicas (uma assistente social e uma mediadora); num outro agrupamento também situado na zona sul de Lisboa foi entrevistada a diretora, a sub-diretora e um educador social.

Os resultados obtidos visam confrontar contextos escolares em São Paulo e em Lisboa com vistas a identificar possíveis aproximações entre Brasil e Portugal sobre as relações de conflitos no espaço escolar, as quais poderão ser exploradas de modo mais sistemático em pesquisas posteriores. As falas dos entrevistados embasam a análise encetada por meio da triangulação com documentos oficiais, medidas legais e a literatura da área, porém, não serão expostas no texto.

A análise de conteúdo das informações coletadas baseou-se nos pressupostos de Bardin (2009). Este procedimento configura-se como um conjunto de estratégias e técnicas utilizadas para análise das comunicações a serem sistematizadas e organizadas por algum critério de semelhança. Após a leitura flutuante, os dados foram postos em perspectiva e sistematizados para elaboração das primeiras inferências pois, segundo Franco (2012), estas conferem à análise de conteúdo relevância teórica:

\section{Produzir inferências é, pois, la raison d'etre da análise de conteúdo [...] uma vez que implica pelo menos uma comparação, já que a informação puramente descritiva, sobre o conteúdo, é de pequeno va- lor. Um dado sobre o conteúdo de uma mensagem [...] é sem sentido até que seja relacionado a outros dados. O vinculo entre eles é representado por alguma forma de teoria. (p. 32).}

Com base na triangulação de fontes de informação e a partir das inferências realizadas por meio da análise de conteúdo, foram identificadas duas grandes dimensões de análise -«programas de governo em ação: diretrizes e normativas» e «a escola face às particularidades das comunidades em que estão localizadas: os casos estudados»- as quais são apresentadas e discutidas nas duas secções seguintes do presente artigo.

\section{Programas de governo em ação: diretrizes e normativas}

No Estado de São Paulo (Brasil) o Programa Sistema de Proteção Escolar foi implantado por meio da Resolução SE 19, de 12/02/2010, apresentando como objetivo instaurar na rede pública de escolas ações para prevenir, mediar e resolver conflitos. O texto preconiza que a Secretaria de Estado da Educação de São Paulo deve disponibilizar recursos humanos próprios, cuja contratação leva em conta fatores de vulnerabilidade e de risco a que estão expostas as escolas da rede estadual de ensino, podendo a unidade escolar contar com até dois docentes para o desempenho das atribuições do Professor Mediador Escolar e Comunitário (PMEC).

Dois documentos orientadores foram elaborados e distribuídos às escolas. O primeiro intitulado «Manual de Normas Gerais de Conduta Escolar» registra que os alunos têm direito a uma educação pública gratuita e de qualidade, sobretudo tendo em vista que as escolas «abrigam alunos e alunas de diferentes idades, níveis de desenvolvimento psicossocial e estratos sociais, que devem receber do Estado atenções adequadas às suas necessidades» (São Paulo, 2009a: 7). No mesmo sentido, o texto sublinha que crianças e adolescentes têm «o direito a tratamento justo e cordial, por todos os integrantes da comunidade escolar». Porém, o documento não se furta a pontuar a relação de deveres e responsabilidades, dentre as quais: «frequentar a escola regular e pontualmente, realizando os esforços necessários para progredir nas 
diversas áreas de sua educação» (São Paulo, 2009a: 9). Outro ponto relevante diz respeito às condutas que afetam o ambiente escolar: faltas disciplinares - passíveis de apuração e aplicação de medidas disciplinares- além de condutas que professores ou a direção escolar considerem incompatíveis com «a manutenção de um ambiente escolar sadio ou inapropriadas ao ensino-aprendizagem, sempre considerando, na caracterização da falta, a idade do aluno e a reincidência do ato». Por orientação do documento, a direção da escola, de imediato, pode aplicar medidas disciplinares de cunho preventivo e repreensivo, sem ouvir inicialmente o Conselho de Escola, podendo ir de advertências verbais à suspensão de até cinco dias das atividades escolares para alunos. (São Paulo, 2009a: 10).

O segundo documento, intitulado «Manual de Proteção Escolar e Promoção da Cidadania», estabelece como objetivo subsidiar as escolas com informações sobre a «natureza das atribuições e competências das diversas instâncias a serem mobilizadas no enfrentamento e mediação dos conflitos que comprometem e distorcem a convivência no ambiente escolar e podem até, eventualmente, extrapolar a dimensão pedagógica» (São Paulo, 2009b: 7). Identifica-se um discurso preocupado em subsidiar os gestores das escolas públicas com informações centradas na ordem do direito, com vistas a prepará-los para enfrentar ações de cunho judicial, se for necessário, pois os problemas devem ser identificados e encaminhados aos órgãos de direito de aplicabilidade da legislação, sem se preocupar de fato em resolver a situação conflituosa e contar com a presença e apoio da família para que possam, juntos, família e escola, assumir suas responsabilidades para com a situação.

Em Portugal o programa TEIP (Territórios de Intervenção Prioritária) surgiu em 1996 e é uma iniciativa do governo nacional, tendo por inspiração medidas políticas semelhantes que haviam começado a ser implementadas previamente em França (Zones d'Éducation Prioritaire) e no Reino Unido (Education Action Zones). A característica comum deste conjunto de medidas de política educativa consiste na procura de rentabilizar instalações, serviços e recursos para o desenvolvimento de estratégias específicas em escolas localizadas em áreas segregadas, com vistas a minimizar efeitos do contexto sócio económico desfavorecido no que se refere aos resultados escolares dos alunos em escolas localizadas nessas localidades. Neste sentido, em Portugal as escolas TEIP têm acesso a instrumentos nem sempre disponíveis nas demais escolas públicas, como sejam equipamentos e professores em maior número e ainda o apoio de outros profissionais (psicólogos, assistentes sociais e mediadores).

Uma avaliação qualitativa do programa realizada pelo próprio Ministério da Educação em 2010 evidenciou que, globalmente, o programa tem efeitos positivos na redução das situações de violência e das taxas de abandono escolar, embora não se tivessem reunido indícios de significativas melhorias dos resultados académicos, permanecendo as classificações dos alunos em exames nacionais claramente abaixo da média registada no país (Abrantes et al., 2013). No que se refere especificamente às situações de conflito nas escolas, a avaliação realizada em 2010 destaca um aumento do número de registos de situações de indisciplina e uma redução do nível de gravidade dessas ocorrências, o que não deverá traduzir necessariamente uma deterioração do clima de convivência nas escolas ao significar uma melhoria quer da capacidade de identificação e registo de situações de indisciplina quer de resposta a estas situações ${ }^{3}$.

Essa avaliação qualitativa realizada em 2010 incidiu sobre as duas primeiras fases do programa TEIP, sendo que no ano letivo 2012/13 teve início o terceiro programa. De acordo com o despacho Normativo n. ${ }^{\circ} 20 / 2012$, publicado em Diário da República em 3 de Outubro de 2012, «justifica-se a criação de um

Informação retirada de: http://www.dge.mec.pt/sites/default/files/EPIPSE/teip_em_numeros_outubro_2010.pdf consultada em 22 de fevereiro de 2017. 
terceiro programa TEIP mais concentrado em torno especialmente das ações que as escolas identificaram como promotoras da aprendizagem e do sucesso educativo, de modo a assegurar maior eficiência na gestão dos recursos disponíveis e maior eficácia nos resultados alcançados». No quadro do programa TEIP3 cada escola deverá elaborar o seu próprio Plano de Melhoria no qual se identificam medidas e ações de intervenção na escola e na comunidade que assegurem a concretização dos objetivos do programa TEIP: promover «a qualidade da aprendizagem e dos resultados escolares dos alunos»; «reduzir o abandono, absenteísmo e indisciplina dos alunos»; favorecer a «transição da escola para a vida ativa»; afirmar a «intervenção da escola como agente educativo e cultural central na vida das comunidades em que se insere» (Artigo 3. ${ }^{\circ}$ do despacho Normativo n. $\left.{ }^{\circ} 20 / 2012\right)$.

O Plano de Melhoria deve ser articulado com o Projeto de Intervenção do Diretor de cada escola (o qual é apresentado quando o mesmo se candidata a esse cargo de direção para o qual é eleito pela comunidade escolar), bem como com o Projeto Educativo da Escola (que é aprovado pelo respectivo Conselho Geral composto por representantes de professores, funcionários, alunos, encarregados de educação e das autoridades locais). Na elaboração dos planos de melhoria, necessários à concessão de apoios através do programa TEIP, devem ser ponderadas as circunstâncias e interesses específicos da comunidade envolvente da escola, bem como contempladas as intervenções de diversos parceiros como sejam as associações de pais, os municípios locais, os centros de saúde e ação social, empresas, associações culturais e desportivas, entre outros.

Embora os dois programas SPE e TEIP tenham diretrizes semelhantes e muitos pontos em comum, diferenças devem ser apontadas, guardadas as dimensões de oferta e atendimento da educação em ambos os países.

A Secretaria de estado da educação de São Paulo é composta por 5.340 escolas, agrupadas em 91 Diretorias de Ensino Regionais (DERs), que atendem a educação básica em dois níveis de ensino: o fundamental e o médio, nas modalidades regular e de Ensino de Jovens e Adultos (EJA). Possui 233.1274 professores, 6.942 especialistas de suporte pedagógico (dirigentes regionais, supervisores de ensino, diretores de escola e coordenadores pedagógicos), 7.755 vice-diretores, 11.781 professores coordenadores, totalizando 26.478 gestores, 4.900 .000 alunos, espalhados pelos 248.209,3 quilômetros quadrados de extensão territorial, com peculiaridades sociais, políticas, econômicas e culturais diversas.

No que tange às funções preconizadas para diretores de escolas, a Resolução SE 52, de 14-8-2013 estabelece um rol de competências previstas, dentre as quais, destaquem-se: conhecer a função social da educação escolar e saber usar a língua portuguesa (oral e escrita), em todas as situações sociais e atividades; compreender que a educação formal promove o desenvolvimento integral do aluno; compreender as dimensões da diferença, da diversidade e do multiculturalismo; conhecer os problemas e conflitos que afetam o convívio social (saúde, segurança, dependência química, educação para o trânsito, pluralidade cultural, ética, sustentabilidade ambiental, orientação sexual, trabalho e consumo); compreender como eles podem provocar preconceitos, manifestações de violência e impactos sociais, políticos, econômicos, ambientais e educacionais, reconhecendo a si mesmo como protagonista e agente transformador no âmbito de sua atuação profissional; aprimorar a capacidade de transformação, iniciativa, criatividade, assim como das implicações éticas e políticas do seu trabalho, pois a sociedade é heterogênica e plural, onde se deve respeitar e valorizar as diferenças ${ }^{5}$.

4 Dados da Coordenadoria de Recursos Humanos (CRHU) da Seesp. Disponível em: http://drhu.edunet.sp.gov.br/a_principal/index.asp, acesso em: 25 abril 2014.
5 http://www.educacao.sp.gov.br/cgrh/wp-content/uploads/2014/06/RESOLU\%C3\%87\%C3\%83O-SE-52-de-14-8-2013, acesso em 18 janeiro 2017. 
Chama a atenção ainda os critérios estabelecidos no que se refere à relação Escola e Comunidade, preconizando que os diretores devem compreender a escola como parte da comunidade escolar, tendo em vista que é constituída pelos professores, equipe gestora, alunos, funcionários, pais e/ou responsáveis pelos alunos. O texto legal também sublinha a necessidade de desenvolver parcerias com a comunidade escolar, considerando o entorno da escola e demais organizações e instituições, com vistas a construir espaços coletivos de participação entre escola, família e comunidade. As disposições legais preveem que diretores exerçam suas funções atendendo adequadamente às demandas sociais e culturais de diferentes segmentos que integram o espaço escolar, em consonância com projetos político-pedagógicos coerentes às necessidades específicas de aprendizagem dos alunos.

No que se refere aos Professores Mediadores Escolares Comunitários (PMECs), estes são selecionados pelas Diretorias de Ensino, seguindo algumas prioridades: em primeiro lugar, titular de cargo docente da própria unidade escolar que se encontre na condição de adido (sem aula atribuída, cumprindo horário de permanência); em segundo, o docente readaptado ${ }^{6}$ e por último, docente ocupante de função atividade. As escolas que se interessam em ingressar no Sistema de Proteção Escolar devem preencher uma manifestação de interesse para contar com este profissional.

Entretanto, problemas no preenchimento dessa função devem ser apontados, pois um dos critérios para seu exercício diz respeito ao fato de o professor não possuir aula atribuída no final do processo de atribuição de classes e aulas. Evidencia-se assim, uma contradição, pois, se o perfil é uma das características fundamentais para ser um PMEC, sem aulas atribuídas sua seleção é transformada em processo consideravelmente aleatório, pois pode ser substituído a cada ano, provocando interrupção nas ações mediadoras e de prevenção à violência propostas nas escolas.

O programa TEIP abrange apenas uma pequena parte dos agrupamentos de escolas/escolas não agrupadas $^{7}$ que em Portugal constituem a rede pública de ensino básico e secundário. De facto, as escolas TEIP abrangem cerca de 10\% dos alunos do ensino básico e secundário em Portugal e distribuem-se por todas as regiões do continente: 49 no Norte, 13 no Centro, 46 em Lisboa e Vale do Tejo, 18 no Alentejo e 11 no Algarve.

Existem escolas que já integravam o programa TEIP anteriormente sendo que, no quadro da terceira fase que se iniciou em 2012/13, o Ministério da Educação (através da Direção Geral de Educação) convidou outras escolas a participar, tendo por base a análise dos respectivos indicadores de desempenho e das características sociais do meio envolvente da escola (Artigo 6. ${ }^{\circ}$ do despacho Normativo n. ${ }^{\circ}$ 20/2012). Consequentemente, foi alargado o número de escolas abrangidas pelo programa TEIP que se cifra, em 2015/16 ${ }^{8}$, em 137 agrupamentos de escolas/escolas não agrupadas localizadas em territórios económica e socialmente desfavorecidos, marcados pela pobreza e exclusão social, nos quais a violência, a indisciplina, o abandono e o insucesso escolar mais se manifestam.

A coordenação das várias intervenções em cada uma das escolas TEIP é assegurada por um equipa multidisciplinar (ver Artigo 10. ${ }^{\circ}$ do Despacho Normativo n. ${ }^{\circ} 20 / 2012$ ) composta pelo diretor do agrupamento de escolas e por outros docentes enquanto coordenadores de departamento, um responsável

\footnotetext{
6 Professor readaptado: professor afastado de suas funções de sala de aula, por motivos de saúde, desenvolvendo outras funções na unidade escolar em conformidade com o rol autorizado pela Comissão de Assuntos de Assistência à Saúde - CAAS.

7 Em Portugal as escolas podem constituir-se como unidades organizacionais isoladas (escolas não agrupadas), mas a grande maioria encontra-se incluída num conjunto de várias escolas que estão geograficamente próximas umas das outras e que partilham recursos financeiros e administrativos (agrupamentos de escolas).

8 Informação obtida na página do Ministério da Educação: http://www.dge.mec.pt/teip, consultada em 19 de abril de 2017.
} 
pela coordenação do plano, um elemento da equipa de autoavaliação do agrupamento e outros elementos da direção cuja inclusão na equipa se julgue adequada, podendo ainda participar nas reuniões os peritos externos (geralmente professores ou investigadores de instituições de ensino superior). $\mathrm{O}$ diretor do agrupamento é eleito pela comunidade escolar e é sempre um professor, sendo que os professores da escolas públicas são contratados na sua maioria por concurso nacional e apenas uma parte diminuta por contratação de escola, estando enquadrados em carreiras formalmente estabelecidas pela legislação nacional. A inclusão no programa TEIP permite a estas escolas contratar diretamente outros profissionais que entendam ter o perfil mais adequado para desenvolver as ações e medidas de intervenção previstas no Plano de Melhoria, como sejam psicólogos, assistentes sociais, mediadores ou educadores sociais, ainda que não existam carreiras formalmente estabelecidas para estes técnicos nas escolas.

\section{A escola face às particularidades das comunidades em que estão localizadas: os casos estudados}

No que se refere às falas dos entrevistados, há mais aproximações do que distanciamentos nos dados obtidos em ambos os países. Senão vejamos.

Na rede estadual de ensino do estado de São Paulo, há um evidente agravamento nas situações de conflito e ampliação de intolerância. Foi possível identificar que, no que se refere a roubo de equipamentos, porte e uso de drogas, violência física de alunos constatou-se que diretores de escolas acionam, prioritariamente, os órgãos colegiados -Associação de Pais e Mestres e Conselhos Escolares. Também realizam palestras e elaboram projetos específicos para esclarecer e tentar superar essas situações. Chama a atenção o fato de acionarem os Professores Mediadores Comunitários - profissionais cujas funções são temporárias, pois todos os anos devem concorrer à função por meio de seleção realizada nas Diretorias de Ensino Regionais- como se fossem atores externos à escola; por fim, optam por chamar a Polícia Militar e/ou a Guarda Civil Metropolitana.

Em casos mais «leves» -agressões verbais, depredação/pichação- outras ações são adotadas prioritariamente, pois diretores afirmam chamar a família, os responsáveis ou os próprios alunos para posteriormente acionarem os órgãos colegiados escolares, realizarem palestras e projetos alternativos. Por último, mobilizam os demais profissionais da equipe de gestão (vice-diretores e coordenadores pedagógicos), assim como os Professores Mediadores Comunitários, estes chamados ainda como último recurso. Entretanto, delegar responsabilidades a outros profissionais na mesma rede de ensino por problemas que deveriam ser assumidos no exercício das próprias funções -no caso, diretores de escolas-, não configura uma novidade no campo da educação, pois o campo de tensão configurado em contextos vulneráveis é desafiador. Nessa direção, transferir responsabilidades e/ou se restringir ao que preconiza o escopo legal e normativo -nem sempre de forma coerente- pode ser uma zona de conforto.

Ainda que numa perspectiva temporal e internacional existam autores que identifiquem a tendência para um aumento da violência em meio escolar na Europa e nos Estados Unidos (Blaya, 2008), constata-se, de acordo com as falas dos entrevistados nas escolas portuguesas, que as situações de conflito não assumem uma expressão alarmante ou não se evidencia que tenham vindo a agravar-se nos últimos tempos. Não obstante, a gestão das situações de conflito e convivência nas escolas é uma preocupação quotidiana, por forma a prevenir a ocorrência de situações de indisciplina e violência em grande número e com gravidade e, no caso das escolas TEIP visitadas, essa preocupação está subjacente a ações de intervenção na própria escola e na relação com a comunidade envolvente. 
Destaca-se a existência de Gabinetes de Apoio ao Aluno ou de Apoio ao Aluno e à Família que complementam a ação dos professores, mediando conflitos entre alunos ou entre alunos e professores que emergem nas salas de aulas e/ou nos recreios e também fora da escola. Destaca-se também as visitas aos domićlios dos alunos com vistas a aproximar a escola dos pais e familiares, bem como para permitir um melhor conhecimento e acompanhamento do contexto e percurso dos alunos. Tal como reconhecem alguns entrevistados, estas ações configuram um alargamento do papel da escola e do professor, no sentido em que a tarefa de ensinar crianças e jovens não dispensa a intervenção sobre os seus contextos de vida dentro e fora da escola, por forma a promover as aprendizagens e prevenir os conflitos.

Para a realização deste tipo de ações dentro e fora da sala de aula e da escola é fundamental o contributo dos técnicos (psicólogo, assistente social, mediador) que cada TEIP contrata em função das atividades previstas no respectivo Plano de Melhoria e que integram a equipa multidisciplinar em conjunto com os professores. Porém, assim como no caso da rede de ensino no estado de São Paulo-Brasil, nas falas dos entrevistados sobressaem as dificuldades que decorrem de muitas vezes existir uma elevada rotatividade destes profissionais em cada escola, pelo facto de terem contratos de trabalho pontuais e não estarem integrados em carreiras profissionais. É que demora meses até que o técnico conheça bem a comunidade escolar e esteja apto a desenvolver o seu trabalho da forma mais adequada e eficaz. Apesar disso, sublinhe-se que a existência de autonomia para delinear um Plano de Melhoria e para decidir a constituição da equipa multidisciplinar emerge como uma particularidade do caso português.

Outra questão recorrentemente apontada por diretores da rede estadual de ensino em São Paulo, e também nas entrevistas realizadas nas escolas de Lisboa, se refere às crescentes práticas de cyberbullying, corroborando achados de estudos na área, pois as tecnologias de informação -por meio das redes sociais- possibilitam ao aluno a divulgação de ofensas a colegas, professores e famílias. Essas atitudes poderiam ser trabalhadas nos currículos escolares a fim de orientar as crianças e os adolescentes para a prática de uma internet segura, baseada no respeito ao outro, e não apenas na implantação de bloqueadores de sites, medida que, isoladamente, não resolve o problema (Oliboni, 2008). Contudo, a cultura escolar sacralizada em práticas de sala de aula cada vez mais distantes da realidade vivenciada por alunos se vê às voltas com a necessidade de responder a questionamentos, inquietações e pequenas incivilidades cotidianas de alunos e que exigem a (re) organização constante de práticas dos profissionais da educação.

Igualmente nos dois países chama a atenção o fato de que as equipes de gestão entrevistadas denotam certo desencanto e desistência no exercício da profissão, elementos que podem indicar um esgotamento no significado da docência - envolvendo funções de gestão- como profissão valorizada pela sociedade e considerada prioritária nas agendas de governo, dados que ratificam pesquisas na área indicando uma crise de identidade profissional no escopo de mudanças sociais, culturais e econômicas e que apontam a necessidade da construção de um novo significado para essa carreira. Como assinala Esteves (1995), a credibilidade que a sociedade creditava à educação como promessa de um futuro melhor deixou de existir e nesse contexto, os professores vêm exercendo o magistério com sentimentos de desilusão e renúncia, elementos aliados à degradação da sua imagem social.

Estudos também indicam fatores que incidem diretamente nas ações em sala de aula e que promovem tensões, sentimentos e emoções negativas, relativos ao contexto da escola: falta de recursos materiais; condições de trabalho limitadoras; aumento da violência no ambiente escolar; acúmulo de exigências; sobrecarga burocrática no trabalho cotidiano. Entretanto, há alguns fatores diferenciadores no Brasil no 
que se refere às condições de trabalho e salário -piores no caso brasileiro- que incidem na satisfação/ insatisfação na carreira do magistério, conforme apontam estudos no campo da formação e práticas de profissionais da educação: baixos salários; desvalorização profissional; estrutura física inadequada de unidades de ensino; carga horária de trabalho excessiva; turmas lotadas; ausência da família no apoio e acompanhamento dos educandos; ausência de regras claras e acordadas que levem os alunos a desenvolverem respeito ao «outro», seja colegas, diretores e/ou professores (Rausch e Dubiella, 2006; Valle, 2006; Scheibe, 2010).

Não obstante, em Portugal, o desencanto com a profissão por parte dos professores surge ainda de forma ainda mais expressiva nas falas dos entrevistados. Esse desencanto relaciona-se, tal como no Brasil, com condições de trabalho e salário, nomeadamente com ausência de progressões na carreira e com os cortes financeiros que nos últimos anos afetaram todos os setores da administração pública reduzindo os rendimentos auferidos pelos trabalhadores e diminuindo os orçamentos para a realização das mais diversas atividades. Porém, o desencanto relaciona-se também com a dimensão e diversidade dos desafios que se colocam à atuação dos professores nas escolas de ensino básico e secundário na contemporaneidade decorrentes das profundas mudanças sociais e económicas (Woods, 2001).

Neste domínio um dos aspectos em que o caso português parece diferenciar-se do brasileiro corresponde à presença significativa de alunos imigrantes de diferentes países africanos, europeus e mesmo do Brasil e ao facto de, como realçam os entrevistados nas escolas de Lisboa, esta situação poder potenciar fortes contrastes culturais que originem conflitos entre alunos, entre alunos e professores ou mesmo entre a escola e as famílias dos alunos. Além disso, a presença das novas tecnologias da informação e comunicação e a instabilidade dos percursos individuais nas sociedades contemporâneas são também indicados como desafios que obrigam a repensar e reconfigurar os modos de funcionamento da escola e o entendimento sobre o seu papel na sociedade na contemporaneidade.

\section{Considerações finais}

Vale destacar os principais pontos convergentes, guardadas as especificidades dos países. Os entrevistados apontaram a necessidade de conhecer a comunidade onde a escola se insere, aprofundar conhecimentos e agregar informações sobre processos de mediação de problemas e conflitos em contextos escolares vulneráveis. No caso de implementação de programas de governo cujos objetivos se voltam ao atendimento de segmentos mais fragilizados da população, saber ouvir as "partes», se posicionar e encaminhar soluções coerentes às demandas locais é essencial, pois essas unidades tornam-se, muitas vezes, foco de atenção da mídia, ampliando a responsabilidade das equipes de gestores, professores e funcionários.

Afirmaram também ter certa dificuldade para lidar com valores sociais complexos no cenário contemporâneo e construir princípios e relações de respeito, pois não se sentem, muitas vezes, suficientemente fundamentados para enfrentar situações desafiadoras, sobretudo no que se refere às condições de vulnerabilidade às quais estão expostas as famílias das regiões onde as escolas se localizam. Nas falas, apontaram aspectos dos contextos vulneráveis que podem interferir até mesmo nas possibilidades do aprendizado: ausência de perspectiva de futuro frente às condições econômicas e culturais vivenciadas pelos alunos; novas configurações familiares que se refletem na escola; o fato de se «perceberem» marginalizados na sociedade, o que pode potencializar sentimentos de fracasso e problemas de autoestima, aprofundando a ausência de sentido do papel social da escola no cenário contemporâneo; influências negativas do contexto (usos e tráfico de droga; alcoolismo; brigas, etc); dificuldades para lidar com culturas 
juvenis que envolvem diferentes linguagens musicais, tipos de roupas, códigos de comunicação; ausência de formação adequada para mediar situações preconceituosos no que se refere a opções sexuais, gênero, etnias e religião, assim como a situações específicas configuradas pelos processos migratórios no continente europeu.

Outro ponto comum que merece destaque diz respeito à aprendizagem institucional das escolas quando localizadas em contextos vulneráveis, sobretudo ao serem instadas a implementarem programas de governo específicos, como estes em pauta. Todos os entrevistados afirmaram a necessidade de as escolas encetarem a construção de um ambiente acolhedor para incluir alunos, famílias e comunidades que podem não deter os mesmos valores sociais e culturais que orientam as práticas escolares, configurando certo campo de tensão no trabalho cotidiano.

Conforme apontado por Martins (2008), no contexto de aprofundamento das transformações políticas, econômicas e culturais no século XXI, a escola volta a assumir uma posição estratégica, enfrentando demandas que pedem urgência na redefinição do modelo vigente, sobretudo considerando-se que as novas tecnologias de informação possibilitam aos alunos acesso a informações, fatos e acontecimentos em tempo real.

Nessa direção, é fundamental a implementação de ações e projetos para subsidiar as escolas e suas equipes de gestão no enfrentamento de situações adversas, sobretudo no que se refere à orientação de alunos e suas famílias sobre regras e procedimentos para exercer direitos e deveres. Em suma, torna-se urgente a instauração de novas formas de acolhimento das diferentes visões de mundo que convivem nas escolas públicas. Entretanto, ressalte-se que professores e diretores são referenciais para os alunos. Se estes profissionais estão desmotivados -levando-os a desempenhar seu trabalho, muitas vezes, de maneira burocrática- dificilmente passarão uma imagem positiva do trabalho escolar e encetarão esforços para reorganizar práticas escolares que renovem ou ressignifiquem o papel da escola. A ausência de efetivação de condições de trabalho e salário dignos para os professores e outros profissionais que atuam nas escolas em ambos os países pode dificultar ainda mais que programas de governo -cujos propósitos partem de pressupostos bem-intencionados- logrem sucesso em sua implementação.

\section{Referências bibliográficas}

Abrantes, Pedro; Roldão, Cristina; Amaral, Patrícia; Mauritt, Rosário (2013): "Born to fail? Some Lessons from a National Programme to Improve Education in Poor Districts". International Studies in Sociology of Education, $23(1), 17-38$.

Akkari, Abdeljalil; Tardiff, Maurice (2011): "A inserção profissional no ensino: alguns pontos de referência sobre uma realidade complexa" in Célia Maria Guimarães et al., (Org.). Formação e profissão docente. Araquara: Junqueira \& Marin.

Alves, Mariana Gaio (2016): "Viver na escola: indisciplina, violência e bullying como desafio educacional". Cadernos de Pesquisa, 46 (161), 594-613,

Alves, Mariana Gaio; Azevedo, Nair; Gonçalves, Teresa (2014): “Satisfação e situação profissional: um estudo com professores nos primeiros anos de carreira”. Revista Educação \& Pesquisa (Brasil), 40 (2), 365-382.

Bardin, Laurence.(1994). Análise de conteúdo. Lisboa: Edições Setenta. 
Biesta, Gert (2012): "Giving Teaching Back to Education: Responding to the Disappearance of the Teacher”. Phenomenology \& Practice, 6 (2), 35-49.

Blaya, Catherine (2008). Violência e maus-tratos em meio escolar. Lisboa: Instituto Piaget.

Clarke, Robert; Keating, W. Francis (1995): “A Fresh Look at Teacher Job Satisfaction”. ERIC Reproduction Service, n. ED, 391-795.

Franco, Maria Laura Puglisi Barbosa (2012). Análise de Conteúdo. Série Pesquisa, Brasilia, $4^{a}$ ed. Campinas: Liber Livro.

Martins, Angela M. (2013): “O campo das políticas públicas de educação: revisão de literatura”. Estudos em Avaliação Educacional (Impresso), 25, 56-70.

Perkins, Cline M. (1991): “A Study to Investigate Experienced Teachers Job Satisfaction and the Teachers' Perception of their Principals' Leadership Style". (Doctoral Dissertation). The University of North Carolina at Chapel Hill. Dissertation Abstracts International, 52, n. A4171.

Raucsh, Rita. B.; Dubiella, Eliani (2013): "Fatores que promoveram mal ou bem-estar ao longo da profissão docente na opinião de professores em fase final de carreira". Rev. Dialogo Educ., Curitiba, 13 (40), 1041-1061. (En línea). www2.pucpr.br/reol/index.php/dialogo?dd99=pdf\&dd1=12307, acesso em 18 novembro 2014.

São Paulo (Estado) (2009 a): "Secretaria de Estado da Educação". Manual de Proteção Escolar e Promoção da Cidadania. Sistema de Proteção Escolar. São Paulo: DE.

São Paulo (Estado) (2009b): “Secretaria de Estado da Educação”. Normas Gerais de Conduta Escolar. Sistema de Proteção Escolar. São Paulo: FDE.

São Paulo (Estado) (2010): "Secretaria de Estado da Educação". Resolução SE n. ' 19, de 12/02/2010. Institui o Sistema de Proteção Escolar na rede estadual de ensino de São Paulo e dá providências correlatas. São Paulo, CENP/DRHU.

Sebastião, João (2013): "Violência na escola, processos de socialização e formas de regulação". Sociologia, Problemas e Práticas, Lisboa, 71, 23-37.

Sebastião, João; Alves, Mariana Gaio; Campos, Joana (2003): "Violência na escola: das políticas aos quotidianos". Sociologia, Problemas e Práticas, Oeiras, 41, 37-62.

Sebastião, João; Alves, Mariana Gaio; Campos, Joana (2010): "Violência na escola e sociedade de risco: uma aproximação ao caso português" in João Sebastião (Org.): Violência na escola: tendências, contextos e olhares. Santarém: Cosmos.

Scheibe, Leda (2010): "Valorização e formação dos professores para a educação básica: Questões desafiadoras para um novo plano nacional de educação". Educ. Soc., Campinas, 31 (112), 981-1000. (En línea). http:/ /www.cedes.unicamp.br, acesso em 16 junho 2014.

Slonje, R.; Smioth, P. K. (2008): “Cyberbullying: Another Main Type of Bullying?”' Scandinavian Journal of Psychology, 49 (2), 147-154.

Stake, Robert E. (2011). Pesquisa qualitativa - estudando como as coisas funcionam. Porto Alegre: Penso. 
Valle, Ione. Ribeiro (2006): "Carreira do magistério: uma escolha profissional deliberada? R. Bras". Est. pedag. Brasilia, 87 (216), 178-187. (En línea). http://rbep.inep.gov.br/index.php/rbep/article/view/792/767, acesso em 18 novembro 2014.

Van Zanten, Agnés. (2006): "Interdependência competitiva e as lógicas de ação das escolas: uma comparação europeia” in João Barroso (Org.): A regulação das políticas públicas de educação: espaços, dinâmicas e atores. Lisboa: Educa.

Woods, Peter (2001): "Ser criativo em relação ao comportamento desviante na escola” in A. M. Pinto, J. C. Conde, M. J. Conde. Indisciplina e violência na escola. Lisboa: Colibri.

\section{Notas biográficas}

Angela Maria Martins. Graduada em Ciências Sociais e Políticas. Mestre em Educação pela Universidade de São Paulo - USP. Doutora em Educação pela Universidade Estadual de Campinas - UNICAMP. Realizou pós-doutorado com bolsa da Coordenação de Aperfeiçoamento de Pessoal de Nível Superior - Capes - no Instituto de Psicologia e Ciências da Educação da Universidade de Lisboa (2008), na área de políticas públicas educacionais. Desde 1996 é pesquisadora da Fundação Carlos Chagas na área de política e gestão da educação. Atualmente é professora do Programa de Pós-Graduação em Educação na Universidade Cidade de São Paulo e coordenadora do Mestrado Profissional Formação de Gestores Educacionais na mesma instituição. Temas de pesquisa: políticas educacionais e gestão da educação básica; metodologias de pesquisa; trajetórias e identidade profissional de diretores e professores.

Mariana Gaio Alves. Doutora e Mestre em Ciências da Educação pela Faculdade de Ciências e Tecnologia da Universidade Nova de Lisboa (UNL). Licenciada em Sociologia pelo Instituto Superior de Ciências do Trabalho e da Empresa (ISCTEIUL). Docente da Faculdade de Ciências e Tecnologia da UNL e coordenadora científica do Centro de Investigação em Educação - Unidade de Investigação em Educação e Desenvolvimento (UIED). É também docente em cursos de mestrado vocacionado para a formação de professores e no programa doutoral em ciências da educação. Temas de investigação: inserção profissional de diplomados de ensino superior; relações entre educação, trabalho e emprego; ensino superior e educação ao longo da vida. 